\title{
Influence of associative bacterial strains on the structure of the microbiocenosis of the rhizosphere of Triticum aestivum $\mathrm{L}$.
}

\author{
$T N$ Melnichuk ${ }^{1,2}, A Y u$ Egovtseva $^{1, *}, S F$ Abdurashytov ${ }^{1}, E R$ Abdurashytova ${ }^{1}, A F$ \\ Radchenko $^{1}, T L$ Ganotskaya $^{1}, L A$ Radchenko ${ }^{1,2}$, and $V S$ Pashtetskiy ${ }^{1}$ \\ ${ }^{1}$ Research Institute of Agriculture of Crimea, 150 Kievskaya str., Simferopol, Republic of Crimea, \\ 295453, Russia \\ ${ }^{2}$ V.I. Vernadsky Crimean Federal University, Prospekt Vernadskogo 4 , Simferopol, Republic of \\ Crimea, 295007, Russia
}

\begin{abstract}
Currently, studies on the use in agriculture of microbial preparations based on plant growth-promoting rhizobacteria are of increasing interest. Mutualistic relationships between microorganisms and plants contribute to increasing the productive potential, immune status of crops. Deciphering of the plant microbiome, the search for effective microsymbionts and the introduction of rhizobacteria into the rhizosphere of plants are current and promising research areas for solving the problem of biologization of agricultural technologies for their cultivation. The purpose of the study was to study the effect of associative bacterial strains on the structure of the microbiocenosis of the rhizosphere and the productivity of winter wheat in the conditions of southern chernozem. The effect of strains associated with Triticum aestivum on the structure of the rhizosphere of winter wheat under the conditions of a field experiment on chernozem southern of the steppe zone of Crimea was established. A metagenomic analysis of the rhizosphere of the varieties Ermak and Bagheera showed the presence of 18 phyla. Seven phyla of prokaryotes: Thaumarchaeota, Acidobacteria, Actinobacteria, Bacteroidetes, Firmicutes, Proteobacteria, and Verrucomicrobia were included in the dominant composition (share above 1\%). The positive effect of newly isolated strains of bacteria associated with $T$. aestivum on plant development was shown.
\end{abstract}

\section{Introduction}

Currently, studies on the use in agriculture of microbial preparations based on plant growthpromoting rhizobacteria are of increasing interest. Associative microorganisms live in the zone of direct influence of plants adjacent to the roots of the soil. They can reach a cell density significantly exceeding the number of plant cells [1] and form complex communities in terms of their taxonomic composition and structurally functional organization on plant roots. Bacteria exert a polyfunctional effect on the plants of the

* Corresponding author: eau82@mail.ru 
trophic type - they provide plant nutrition, the protective type - promote plant resistance to phytopathogenic microbes and phytophages [2-3].

Mutualistic relationships between microorganisms and plants contribute to increasing the productive potential and immune status of crops, providing them with elements of mineral nutrition and stimulating growth and development [4-5]. The search for effective microsymbionts and the introduction of strains into the rhizosphere of plants are current and promising research areas for solving the problem of biologization of agricultural technologies for their cultivation. The study of the quantitative composition of soil microbial communities and the calculation of ecological and trophic indices allows us to determine the direction of mineralization processes in the transformation of organic matter, which is an important basis for solving issues of increasing plant productivity, product quality and fertility of agroecosystems.

Currently, the spectrum of bacteria that have a positive effect on plants is expanding thanks to active research in this area. However, the question of the relationship between bacteria and plants in plant-microbial associations requires further fundamental study. Therefore, deciphering of the plant microbiome is crucial for identifying microorganisms that can be used to improve plant growth and health.

The purpose of the study was to explore the effect of associative bacterial strains on the structure of the microbiocenosis of the rhizosphere and the productivity of winter wheat in the conditions of southern chernozem.

\section{Materials and methods}

\subsection{Setting up an experiment}

Studies on the effect of associative strains of bacteria on soft wheat on its productivity were carried out in a 10-field selection crop rotation of the introduction and technology department in field husbandry and animal husbandry of the Federal State Budget Scientific Research Institute of Agriculture of Crimea. Triticum aestivum L. was sown on the predecessor of black steam. The preparation of black steam and the technology for growing winter grains were generally accepted for the region and differed only in the studied factors. The experiments were carried out according to generally accepted methods [6]. The area of the site in the experiment was $25 \mathrm{~m}^{2}$, the repetition-four times. The distribution of plots was systematic, with an offset. Sowing was carried out at the optimum sowing period for the zone (second decade of October) with the SKS 6-10 selection seeder.

The experiment is two-factor. The experimental scheme is presented in table 1.

Table 1. Scheme of experiment in studying the influence of associative strains of bacteria to $\mathrm{T}$. aestivum on the productivity of winter wheat varieties.

\begin{tabular}{|c|c|c|}
\hline No & Variety (Factor A) & bacterial strain (Factor B) \\
\hline 1 & Ermak & \multirow{2}{*}{$\begin{array}{c}\text { P4, M3, B5, R1, L1, C (Control -without inoculation of } \\
\text { seeds) }\end{array}$} \\
\hline 2 & Bagheera & \\
\hline
\end{tabular}

Strains of Pseudomonas fluorescens P4, Paenarthrobacter nitroguajacolicus L1, P. nitroguajacolicus M3, Bacillus sp. B5 and Agrobacterium tumefaciens R1 were isolated from the rhizosphere of winter soft wheat. Isolation was performed by a method for obtaining roots isolated from the external environment in a Leonard vessel [7]. 
Studies of the rhizosphere of T. aestivum were conducted in 2019 on two varieties. Bagheera; the originator - is Stavropol Research Institute of Agriculture (Mikhaylovsk, Russia). It is resistant to attack by brown rust and powdery mildew; moderately stable to Septoria; medium-resistant to drought, frost and lodging. Ermak; the originator - is Agricultural Research Centre "Donskoy" (Zernograd, Russia). It is resistant to attack by brown rust and Smut (fungus); medium-sensitive to powdery mildew; high drought resistant, winter hardiness is above the average level.

The plants were taken at the booting stage.

\subsection{Soil and Climate Conditions}

The southern chernozem (by WRB classification Haplic Chernozem, Loamic, Aric of Crimean Steppe Zone is weakly-humify. It is developed on Quaternary yellowish-brown loess-like light clays. The thickness of the humus layer (horizon A) is $24-36 \mathrm{~cm}$, totally 57 $70 \mathrm{~cm}$. The humus content in the plow horizon is $2.4-2.7 \% .100 \mathrm{~g}$ of dry soil from plow layer contain $5.2 \mathrm{mg}$ of easily hydrolyzable nitrogen, $1.0-2.5 \mathrm{mg}$ of $\mathrm{P} 2 \mathrm{O} 5,42 \mathrm{mg}$ of $\mathrm{K}_{2} \mathrm{O}$. The total nitrogen is $0.11-0.12 \%$, phosphorus - $0.20 \%$, potassium $-1.96 \%$. The mechanical composition of the soil is slightly clayey. The structure is lumpy, dustypowdery. The volumetric mass of a meter layer of soil is $1.24 \mathrm{~g} \mathrm{~cm}-3$ Maximum hygroscopicity is $8.9 \%$. Wilting humidity is $11.5 \%$ of dry soil, or $47.3 \%$ of the lowest field capacity (LFC). LFC in meter layer of soil - 23,8\% of dry soil. The reaction of the soil solution in the upper horizon is slightly alkaline ( $\mathrm{pH}$ 7.7-7.9).

The climate of the Steppe is arid (Hydrothermal coefficient (HTC) - 0,7), moderately hot with moderately mild winter. The average annual air temperature is $9.7-10.5{ }^{\circ} \mathrm{C}$. Vegetation thaw is possible in $35 \%$ of winters. The period without frosts is 171 days. The sum of temperatures above $+10{ }^{\circ} \mathrm{C}$ is $3280{ }^{\circ} \mathrm{C}$. The annual precipitation is $435 \mathrm{~mm}$. During the active vegetation period falls $285 \mathrm{~mm}$. The annual volatility is $843 \mathrm{~mm}$. Strong winds are 28-30 days per year. The number of days with dry winds is 10-19. The probability of droughts for most of the territory is $40-50 \%$ of years [8].

Quantity of soil microorganisms of the main ecological-trophic groups (ammonifying and amylolytic bacteria, nitrogen fixing bacteria, micromycetes, cellulosolytics, actinomycetes, oligotrophs and pedotrophs) in winter wheat rhizosphere was determined according to conventional methods $[7,9]$, as well as the oligotrophy index, mineralization coefficients, oligonitrophilicity and pedotrophy [10-11]. It is shown in colony-forming units (CFU) per g of dry soil. The results were processed by statistical methods [6].

\subsection{DNA extraction and sequencing}

In the research process, modern approaches were used to study the structure of the rhizosphere microbiome using high-throughput sequencing of 16S rRNA gene libraries (taxonomic analysis).

For this, total DNA was isolated from soil samples using the PowerSoil DNA Isolation Kit (Qiagen, Germany), on a Vortex Genee-2 instrument (Mo-bio, USA) according to the manufacturer's protocol. DNA purification was carried out electrophoretically followed by extraction from agarose gel [12]. Purified DNA preparations were used to create libraries of the 16S rRNA marker gene by PCR using universal primers for the V4 variable region: F515 / R806 (GTGCCAGCMGCCGCGGTAA / GGACTACVSGGGTATCTAAT) [13], as well as by connecting adapters and unique barcodes of the Illumina. Further library preparation and sequencing was carried out in accordance with the manufacturer's recommendations on the «Illumina MiSeq» platform (Illumina, USA) using the MiSeq ${ }^{\circledR}$ 
ReagentKit v3 reagent kit (600 cycle) with two-sided reading $(2 * 300 \mathrm{n})$ in the Core Centrum 'Genomic Technologies, Proteomics and Cell Biology' (ARRIAM).

The initial processing of the obtained data, namely, demultiplexing of samples and removal of adapters, was carried out by Illumina software (Illumina Inc., USA). The software packages dada2 [14], phyloseq [15], and DECIPHER [16] were used for subsequent denoising, combining sequences, removing chimeric readings, restoring the original phylotypes (ASV, Amplicon sequence variant), and further taxonomic classification of the resulting ASVs, which were carried out in software environment R. Means of the QIIME software package [17] were used to represent taxonomic analysis data. The taxonomic and statistical analysis of the results was obtained using the PAST3 software packages [18].

\section{Results and discussion}

The obtained data on the number of microorganisms of the main ecological and trophic groups of southern Chernozem of the rhizosphere Triticum aestivum, which are an indicator of the state of soil microbocenosis [19], allowed us to establish the influence of strains of associative bacteria.

The number of microorganisms that transform mainly organic nitrogen compounds was higher than the control under the influence of the L1 strain in the rhizosphere of both varieties: Ermak - by $33.3 \%$, Bagheera-by $41.3 \%$ (fig. 1).

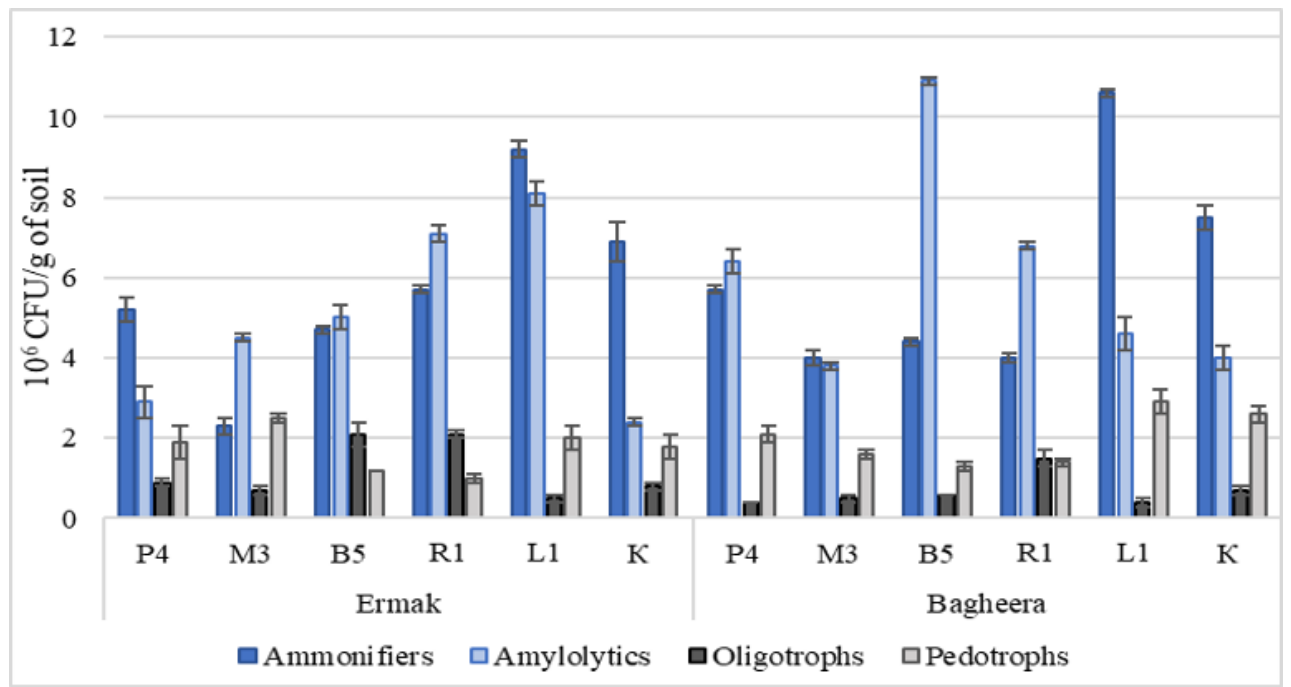

Fig. 1. Influence of strains on the number microorganisms of the rhizosphere winter wheat (field experiment, 2019).

The effect of inoculation on the number of amylolytic that use nitrogen from the soil in the form of mineral compounds was more significant on both varieties. Thus, on the Ermak variety, all strains, with the exception of $\mathrm{P} 4$, which was at the control level, contributed to its increase by 1.9-3.4 times. The number of amylolytics remained at the control level with the M3 and L1 strains, while the other variants showed an increase of 1.6-2.7 times in the rhizosphere of the Bagheera variety. Inoculation with the R1 strain contributed to an increase in the number of oligotrophs in the rhizosphere of both varieties: Ermak -2.6 times (as with the B5 strain), Bagheera -2.1 times. The number of pedotrophs under the 
influence of these strains decreased in both varieties. Its increase by 1.4 times was observedunder the influence of the M3 strain only on the Ermak variety.

Approximately $1 / 3$ of biological nitrogen is accounted for by nitrogen fixed by associative microorganisms in the rhizosphere of non-legume plants [20]. Inoculation with strains L1 and B5 contribute to a better development of nitrogen-fixing bacteria of the rhizosphere of varieties Ermak, their total number is 1.4 and 1.3 times higher than control, with strain M3 marked decline, as in most of the options on the grade of Bagheera, except for L1, where the increase amounted to 1.2 times (table 2). The contents of Azotobacter under the influence of the strains (except B5) increased by $6.7-16.0 \%$ in the rhizosphere of both varieties. The R1 strain contributed to its decrease by 3.0 times.

Table 2. Influence of strains on the number of nitrogen-fixing microorganisms of the rhizosphere wheat (field experiment, 2019).

\begin{tabular}{|c|c|c|c|}
\hline Variety & \multirow[t]{2}{*}{ Treatment } & \multicolumn{2}{|c|}{ Nitrogen-fixing microorganisms } \\
\hline & & Total, $10^{6} \mathrm{CFU} / \mathrm{g}$ of soil & Azotobacter, $\%$ \\
\hline \multirow{6}{*}{ 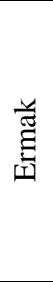 } & P 4 & $3,6 \pm 0,2$ & $96,0 \pm 2,3$ \\
\hline & M3 & $2,6 \pm 0,2$ & $90,7 \pm 2,7$ \\
\hline & B5 & $4,8 \pm 0,1$ & $73,3 \pm 6,7$ \\
\hline & R1 & $4,1 \pm 0,3$ & $97,3 \pm 1,3$ \\
\hline & L1 & $5,3 \pm 0,4$ & $94,7 \pm 1,3$ \\
\hline & $\begin{array}{l}\mathrm{C} \text { (without } \\
\text { inoculation) }\end{array}$ & $3,8 \pm 0,1$ & $81,3 \pm 1,3$ \\
\hline \multirow{6}{*}{ 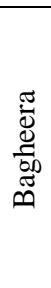 } & P 4 & $3,7 \pm 0,1$ & $92,0 \pm 2,3$ \\
\hline & M3 & $2,7 \pm 0,2$ & $92,0 \pm 0,0$ \\
\hline & B5 & $2,4 \pm 0,2$ & $81,3 \pm 1,3$ \\
\hline & R1 & $2,2 \pm 0,1$ & $26,7 \pm 2,7$ \\
\hline & L1 & $6,2 \pm 0,3$ & $88,0 \pm 4,6$ \\
\hline & $\begin{array}{c}\mathrm{C} \text { (without } \\
\text { inoculation) }\end{array}$ & $5,0 \pm 0,3$ & $81,3 \pm 1,3$ \\
\hline
\end{tabular}

The number of actinobacteria, whose ecological role mainly consists in the destruction of complex resistant substrates, synthesis and decomposition of humic substances, increased 2.0 times under the influence of L1, R1 and B5 strains in the Ermak variety, while a decrease of 1.2 to 6.0 times was observed in all variants in the Bagheera variety (fig. 2). 


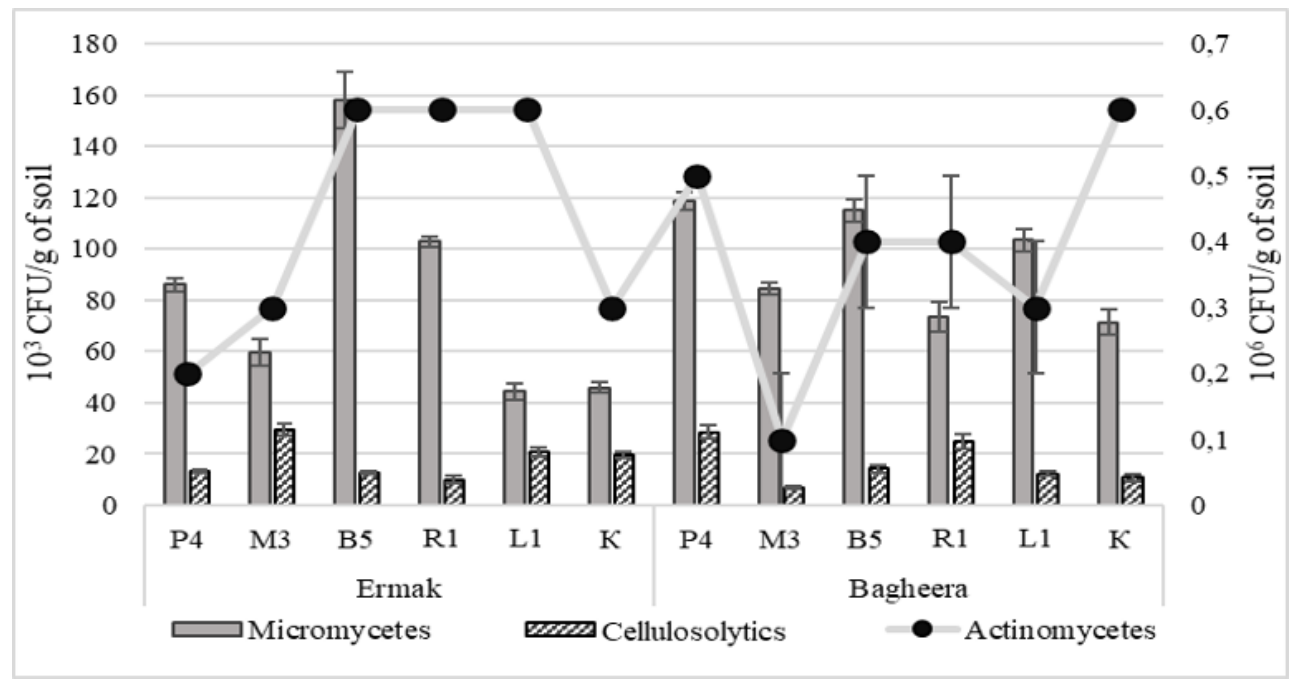

Fig. 2. Influence of strains on the number microorganisms of the rhizosphere wheat (field experiment, 2019).

Soil fungi represent a large ecological group involved in the mineralization of organic residues of plants and animals and in the formation of humus, are the main destructors of complex compounds [21], making it possible for their further use by other organisms. The number of micromycetes in the rhizosphere of both varieties increased by 1.2-3.4 times under the influence of inoculation, with the exception of L1 strains in the Ermak variety and R1 in the Bagheera variety, which were at the control level. The number of microorganisms in the wheat rhizosphere reacted to inoculation by strains in inverse dependence on the variety. Strains P4, B5 and R1 contributed to its decrease by 1.5-2.0 times in the Ermak variety, while in the Bagheera variety-an increase by 1.3-2.7 times. An increase in the number of cellulosolytics by 1.5 times in the Ermak variety and the same decrease in the Bagheera variety was observed in the variant with the M3 strain. These indicators remained at the control level in the variant with the L1 strain.

Microbial biomass is a labile component of organic matter, primarily reacts to environmental changes, and reflects the trend of accumulation or mineralization of soil organic matter [22]. The calculation of coefficients and indices indicating the direction of mineralization processes in the soil allowed us to establish that inoculation contributes to their activation (fig. 3). 


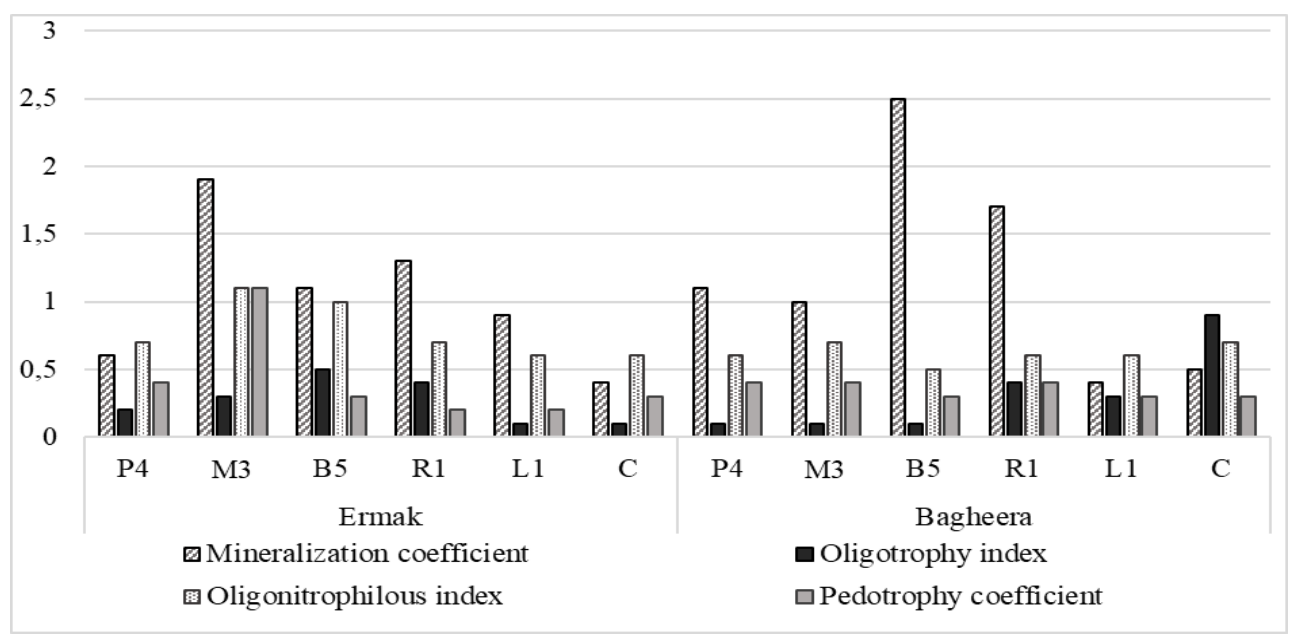

Fig. 3. Influence of strains on the direction of mineralization processes of the rhizosphere of winter wheat (field experiment, 2019).

Growth processes are an integral indicator of the physiological state of plants [23]. Positive impact new isolated strains on plant growth of two wheat varieties installed in the flowering stage of plants (table 3). The effect of strain B5 to the length of the shoot have varieties Ermak, the increase was $4.3 \mathrm{~cm}(5,9 \%)$, on the mass of the dried escape and $0.5 \mathrm{~g}$ (31.2 per cent) compared with the control. The weight was even higher-by $1.0 \mathrm{~g}(62.5 \%)$ for the Bagheera variety. The R1 strain also contributed to a $0.6 \mathrm{~g}(37.5 \%)$ weight increase in the Ermak variety, as did L1 in the Bagheera variety by $0.8 \mathrm{~g} \mathrm{(50 \% ).}$

Table 3. The influence of isolated strains on the development of plants of two varieties of wheat (field experiment, 2019).

\begin{tabular}{|c|c|c|c|c|}
\hline \multirow{3}{*}{$\begin{array}{l}\text { Treatment } \\
\text { (factor B) }\end{array}$} & \multicolumn{2}{|c|}{ Shoot length, $\mathrm{cm}$} & \multicolumn{2}{|c|}{ Weight of dried shoot, $g$} \\
\hline & \multicolumn{4}{|c|}{ Varieties (factor A) } \\
\hline & Ermak & Bagheera & Ermak & Bagheera \\
\hline P4 & 74,8 & 70,4 & 1,7 & 1,4 \\
\hline M3 & 73,1 & 72,8 & 1,9 & 1,7 \\
\hline B5 & 77,3 & 70,6 & 2,1 & 2,6 \\
\hline R1 & 74,3 & $\mathbf{7 4 , 3}$ & 2,2 & 2,0 \\
\hline L1 & 73,7 & 73,6 & 1,8 & 2,4 \\
\hline $\begin{array}{c}\text { C(without } \\
\text { inoculation)) }\end{array}$ & 73,0 & 72,4 & 1,6 & 1,6 \\
\hline $\begin{array}{l}\mathrm{SRD}_{05} \\
\text { factor A } \\
\text { factor B }\end{array}$ & \multicolumn{2}{|c|}{$\begin{array}{l}3,8 \\
1,5 \\
2,7\end{array}$} & \multicolumn{2}{|c|}{$\begin{array}{l}0,6 \\
0,2 \\
0,4\end{array}$} \\
\hline
\end{tabular}

Metagenomic analysis of microbial communities of the Ermak and Bagheera varieties showed the presence of representatives of 18 phyla belonging to the domains of archaea and bacteria. A significant proportion were uncertain representatives across domains, which ranged from 40.8 to $43.3 \%$, depending on cultivar and inoculation with strain (fig. 4). Seven phyla: Thaumarchaeota, Acidobacteria, Actinobacteria, Bacteroidetes, Firmicutes, Proteobacteria and Verrucomicrobia became part of the dominant (the share above 1\%). The percentage of undefined phylotypes from the bacteria domain was $1.4-1.7 \%$.

The representation of the archae phylum Thaumarchaeota, which are oxidizing agents of ammonia and play a key role in the nitrogen cycle [24], was in the range of $1.7-2.1 \%$ in the variety Ermak and $1.5-2.4 \%$ in the variety Bagheera. Strain L1 contributed to a slight 
increase in both varieties. Inoculation contributed to an increase in the percentage of Acidobacteria phylum bacteria, with the exception of the variant with strain $\mathrm{R} 1$, where a slight decrease was noted compared with the control. The maximum indices of their share were noted with inoculation of B5 and M3, which were 1.7 and 1.3 times higher than the control in the Ermak variety and 1.5 and 1.7 times in the Bagheera variety, respectively. 
(a)

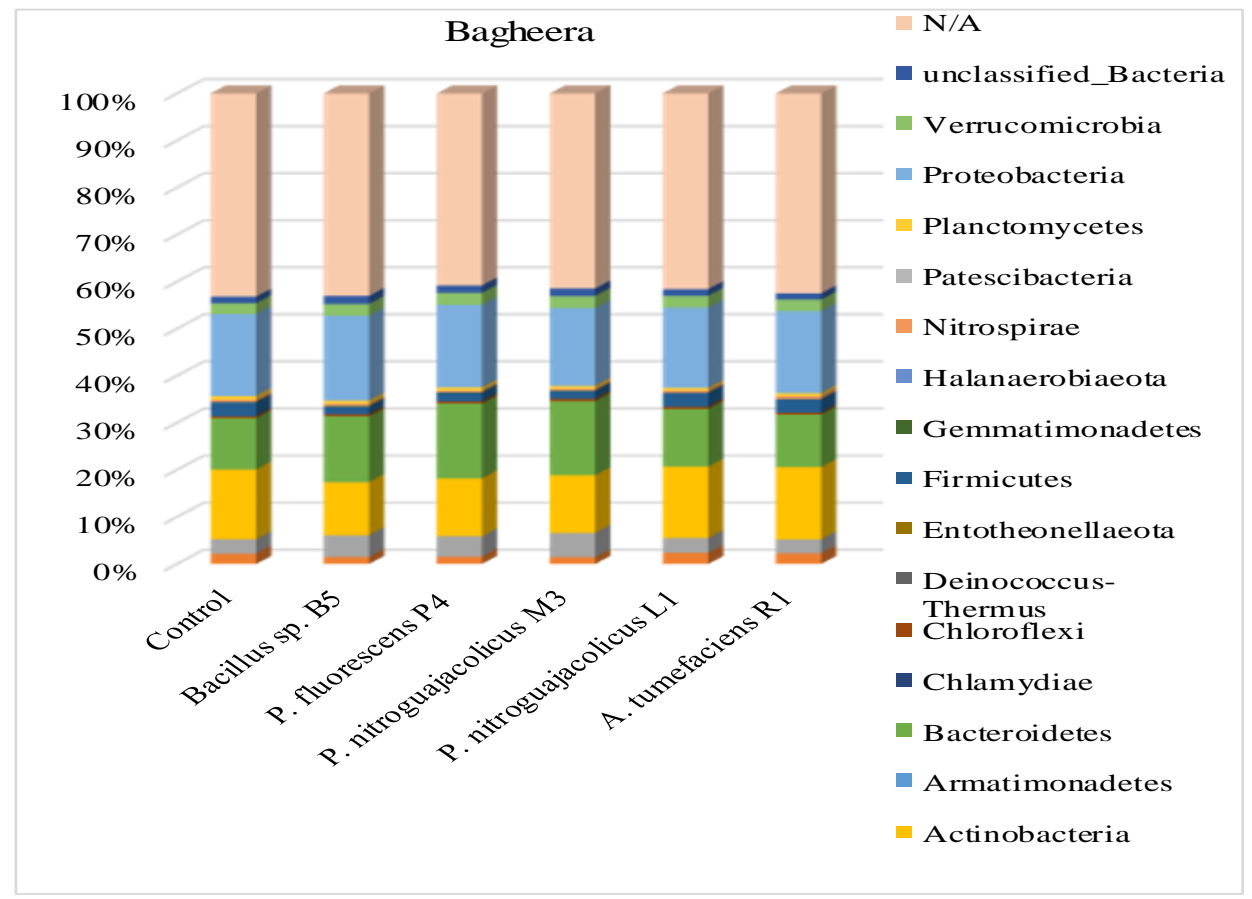

(b)

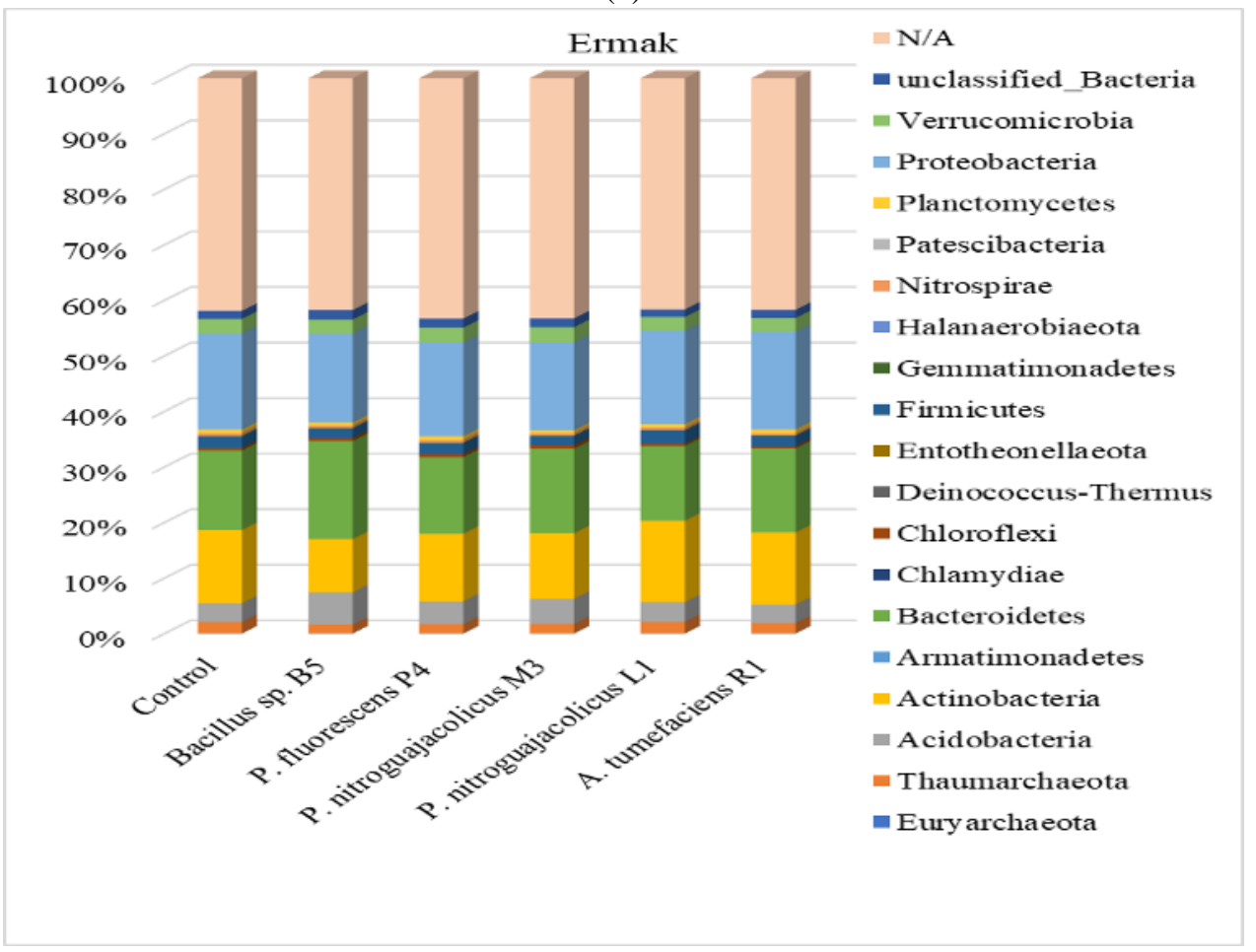

Fig. 4. Influence of associative bacterial strains on the taxonomic structure of the rhizosphere microbiome of wheat varieties. 
Representatives of Actinobacteria are known for their high potential for bioremediation [25], as well as their adaptability to dry and warm conditions [26], which can explain its share in the studied microbiome by an order of magnitude higher. The maximum decrease in the share of 1.3 and 1.4 times was noted under the influence of strain B5 in both varieties. The highest indicator of $14.7 \%$ was observed in the variant with L1 on the cultivar Ermak, in the control 13.2\%. An increase was noted on the Bagheera cultivar in this variant, but the maximum with a share of $15.4 \%$ with inoculation of $\mathrm{R} 1$ at $14.8 \%$ in the control. The values of the share of the same order were observed in representatives of the phylum Bacteroidetes, which increased under the influence of inoculation in the Bagheera variety from $10.96 \%$ in the control to $11.13 \%$ (minimum value) in the variant with $\mathrm{R} 1$ and $15.9 \%$ (maximum value) with the strain $\mathrm{P} 4$. Their representation in the control was $14.26 \%$ in the variety Ermak and increased under the influence of strains R1, M3 and B5 to 15.08, 15.20 and $17.62 \%$, respectively. A slight decrease was noted in the variants with P4 (13.75\%) and with L1 (13.42\%).

Representatives of the Firmicutes phylum participate in the decomposition of complex organic substances, serve to maintain the stability of the rhizosphere microbiome, and contribute to soil bioremediation [27-29]. The representatives of this filum decreased under the influence of strains in both varieties in the conditions of southern chernozem. The exception was the variant L1, where the share was slightly $(0.3 \%)$ higher, and in the Bagheera variety at the control level $(2.9 \%)$.

Phylum Proteobacteria, representing the largest group of bacteria, responded by reducing the proportion to inoculation, with the exception of the $\mathrm{R} 1$ variant, with a slight increase of $0.3 \%$ in the rhizosphere of the Ermak variety. The most significant decrease of $1.5 \%$ was observed in the variant with M3. Strain M3 also contributed to a decrease of $0.8 \%$ in the variety Bagheera, strain B5-increase of $0.6 \%$, in other cases, the indicators were close to control.

Trends in the insignificant increase in the share of Verrucomicrobia, whose representatives are indicators of the chemical properties of the soil associated with fertility [30], were noted under the influence of inoculation in the Bagheera variety, while in the Ermak variety only in variants with P4 and M3 in comparison with the control. A decrease in the proportion among minor representatives of the phylum of archaea Euryarchaeota was noted under the influence of inoculation from 1.2 times with strain L1 to 5 times with P4 in the rhizosphere of the Bagheera variety, with strains B5 and M3 they were not detected.

\section{Conclusion}

The effect of strains associated with $T$. aestivum L. on the microbocenosis of the rhizosphere of winter wheat under the conditions of a field experiment on chernozem southern of the Steppe zone of Crimea was established. Inoculation with strains L1 and B5 contributed to the better development of nitrogen fixers of the rhizosphere of the Ermak variety; their total number was 1.4 and 1.3 times higher than the control.

A metagenomic analysis of the rhizosphere of the varieties Ermak and Bagheera showed the presence of 18 phyla belonging to the archaea and bacterial domains. A significant proportion were unidentified representatives among the domains whose indices ranged from 40.8 to $43.3 \%$ depending on the variety and its inoculation with the strain. Seven phyla of prokaryotes: Thaumarchaeota, Acidobacteria, Actinobacteria, Bacteroidetes, Firmicutes, Proteobacteria, and Verrucomicrobia were included in the dominant composition (share above 1\%). The proportion of undefined phylotypes from the Bacteria domain was $1.4-1.7 \%$. 
The positive effect of newly isolated strains of bacteria associated with T. aestivum on plant development was shown. So, inoculation with strains B5, L1, R1 led to an increase in biometric indicators, the most pronounced effect was observed in relation to the weight of dried shoots of plants in both varieties.

The work was carried out within the Framework of the State Assignment of Fundamental Research No. 0834-2015-0005 and with the support of the RFBR grant A18-016-00197.

\section{References}

1. Mendes R, Garbeva P, Raaijmakers J M 2013 FEMS microbiology reviews 37(5) 634663

2. Naumetov R V Sabitov M M 2017 Modern Scientist 5 26-33

3. Kumar A, Bahadur I, Maurya B R, Raghuwanshi R, Meena V S, Singh D K and Dixit J 2015 J Pure Appl Microbiol 9(1) 715-724

4. Tikhonovich I A, Provorov N A 2011 Agricultural biology: plant biology series 3 3-9

5. Dmitricheva D S, Yapparov A Kh, Degtyareva I A 2011 Uchenye zapiski KGAVM im NE Bauman 207 186-190

6. Dospekhov B A 2014 Methods of field research (with the basics of statistical processing of research results) (Moscow: Alians)

7. Volkogon V V 2010 Experimental soil microbiology (Kiev: Agrarna Nauka)

8. Pashtetskiy V S 2015 Scientific basis for the optimization of agrolandscapes and effective agricultural production of the Republic of Crimea (Simferopol: Arial)

9. Tepper E Z, Shilnikova V K, Pereverzeva G I 2005 Workshop on Microbiology (Moscow: Drofa)

10. Andriyuk K I, Iytins'ka G O, Antypchuk A F, Valagurova O V, Kozyirits'ka V E 2001 Functioning of microbial soil groups under anthropogenic loading conditions (Kiev: Oberegy)

11. Titova V I, Kozlov A V 2012 Methods for assessing the functioning of the soil microbiocenosis involved in the transformation of organic matter: Scientific and methodological manual (Nizhniy Novgorod: Agrarian academy of Nizhniy Novgorod)

12. Andronov E E, Pinaev A G and Pershina E V 2011 Isolation of DNA from soil samples (St. Petersburg: PC "Association Venta")

13. Bates S T, Berg-Lyons J G, Caporaso W A et al 2010 ISME J. 5 908-917

14. Callahan B J, McMurdie P J, Rosen M J, Han A W, Johnson A J A, Holmes S P 2016 Nature Methods 13 581-583 doi:10.1038/nmeth.3869.

15. McMurdie and Holmes 2013 PLoS ONE 8(4) e61217

16. Wright E S 2016 The R Journal 8(1) 352-359

17. Caporaso J G, Kuczynski J, Stombaugh J et al 2010 Nature methods 7(5) 335-336 doi:10.1038/nmeth.f.303

18. Hammer Ø, Harper D A T and Ryan P D 2001 Palaeontologia Electronica 4 (1) 9

19. Schloter M., Nannipieri P., Sørensen S J and van Elsas J D 2018 Biology and Fertility of Soils 54(1) 1-10

20. Tikhonovich I A, Zavalin A A 2016 Plodorodiye 5 28-32

21. Shirokikh I G, Kozlova L M, Shirokikh A A, Popov F A and Tovstik E V 2017 Eurasian soil science 50(7) 826-831 
22. Zav'ylovaa N E, Vasbievaa M T, Fomina D S 2020 Soil Science 3 372-378 doi: 10.31857 / s0032180x20030120

23. Gruznova K A, Bashmakov D I, Brazaitytė A, Duchovskis P, Lukatkin A S 2017 Zemdirbyste-Agriculture 104(4)

24. Lu X, Seuradge B J and Neufeld J D 2017 FEMS microbiology ecology 93(2) fiw246

25. Polti M A, Aparicio J D, Benimeli C S and Amoroso M J 2014 International Biodeterioration \& Biodegradation 88 48-55

26. Pershina E V, Kutovaya O V, Kogut B M, Andronov E E 2017 The main achievements and prospects of soil metagenomics (St. Petersburg: Inform-Navigator)

27. Wei Z, Hu X, Li X, Zhang Y, Jiang L, Li J 2017 PLoS ONE 12(4) e0174411 doi.org/10.1371/journal. pone.0174411

28. Hartmann M, Frey B, Mayer J, Mäder P, Widmer F 2015 ISME J 9(5) 1177-1194

29. Gupta A, Dutta A, Sarkar J, Panigrahi M K and Sar P 2018 Frontiers in microbiology 9 2882

30. Navarrete A A, Soares T, Rossetto R, Antonie van Veen J, Tsai S M, Kuramae E E 2015 Antonie van Leeuwenhoek 108 741-752 doi 10.1007/s10482-015-0530-3 